\title{
Synergistic Antifungal Activity of Phellodendri Cortex and Magnoliae Cortex against Candida albicans
}

\author{
Hyunjeong $\mathrm{NA}^{1} \cdot$ Tae-Jong $\mathrm{KIM}^{1, \dagger}$
}

\begin{abstract}
Many studies on plant extracts have been reported for the treatment of candidiasis caused by Candida albicans, a representative fungal infection. This study demonstrates the synergistic antifungal activity of the combination of Phellodendri Cortex and Magnoliae Cortex, previously reported to have antifungal efficacy. Considering the antifungal efficacy and the separation of the active constituents, berberine and magnolol, hot water extraction and carbon dioxide supercritical extraction were selected for Phellodendri Cortex and Magnoliae Cortex, respectively. A combination of $0.55 \mathrm{~g} / \mathrm{L}$ hot water extract of Phellodendri Cortex and $0.59 \mathrm{~g} / \mathrm{L}$ carbon dioxide supercritical extract of Magnoliae Cortex showed synergistic antifungal activity. The synergistic antifungal activity of $160 \mu \mathrm{M}$ berberine and $100 \mu \mathrm{M}$ magnolol, which are representative antifungal compounds of Phellodendri Cortex and Magnoliae Cortex, respectively, contributes to the synergistic antifungal effect of their extracts. The additive decrease in cellular ergosterol level and the increased antifungal efficacy by extracellular ergosterol suggest that disruption of the biological function of ergosterol in the cell membrane is not responsible for the synergistic antifungal activity of berberine and magnolol. Synergistic cellular release of chromosomal DNA upon mixing berberine and magnolol indicates that disruption of the cellular structure is responsible for the synergistic antifungal effect of berberine and magnolol.
\end{abstract}

Keywords: phellodendri cortex, magnoliae cortex, antifungal activity, synergistic activity, Candida albicans

\section{INTRODUCTION}

Candida is a common fungus that exists on the skin, as well as in the gastrointestinal and urinary tracts, and it is a representative fungal infectious agent as an opportunistic pathogen for humans (Enoch et al., 2006; Pfaller and Diekema, 2007; Soll et al., 1991; Yapar, 2014). The strain most commonly isolated from Candida-infected patients is $C$. albicans, suggesting that it is the major causative agent of Candida infection ( $\mathrm{Ng}$ et al., 2015; Pfaller and Diekema, 2007). C. albicans causes candide- mia, Candida vaginitis, oral candidiasis, and invasive candidiasis in the human body. Among these diseases, invasive candidiasis has a mortality rate of $46 \%-75 \%$ (Brown et al., 2012; Richter et al., 2005; Sandven, 2000; Taylor and Raja, 2021). Oral candidiasis leads to dysgeusia, dysphagia, loss of appetite, and weight loss (Sharon and Fazel, 2010) and candida vaginitis decreases the quality of life of women due to symptoms such as odor, itching, fever, and difficulty urinating (Landers et al., 2004). Therefore, it is important to develop a therapeutic agent for $C$. albicans infection.

\footnotetext{
Date Received November 19, 2021, Date Revised December 25, 2021, Date Accepted December 28, 2021

${ }^{1}$ Department of Forest Products and Biotechnology, College of Science and Technology, Kookmin University, Seoul 02707, Korea

† Corresponding author: Tae-Jong KIM (e-mail: bigbell@kookmin.ac.kr, https://orcid.org/0000-0002-7483-0432)

(C) Copyright 2022 The Korean Society of Wood Science \& Technology. This is an Open-Access article distributed under the terms of the Creative Commons Attribution Non-Commercial License (http://creativecommons.org/licenses/by-nc/4.0/) which permits unrestricted non-commercial use, distribution, and reproduction in any medium, provided the original work is properly cited.
} 
It has been reported that the biological mechanisms behind the activity of antifungal agents against $C$. albicans include inhibition of the synthesis of ergosterol, destruction of the membrane structure by binding to ergosterol, and inhibition of glucan synthesis (de Oliveira Santos et al., 2018). Fluconazole is commonly used for treating candidiasis because it exhibits higher efficacy at lower concentrations than other antifungal agents (Saag and Dismukes, 1988). Fluconazole inhibits ergosterol synthesis by acting on sterol demethylase, which transforms lanosterol into ergosterol (Vincent-Ballereau et al., 1991). However, antifungal-resistant C. albicans infections are being reported frequently and fluconazoleresistant $C$. albicans has been more widely reported than other resistant Candida species (Espinel-Ingroff et al., 2014; Pfaller et al., 2008b; Pristov and Ghannoum, 2019; Rex et al., 1995; Whaley et al., 2017). In addition to the problem of resistant Candida, given that fungi are eukaryotes like humans, treatment is always associated with a particular risk of side effects (de Oliveira Santos et al., 2018).

Many studies have been conducted to overcome the limitations of antifungal agents (Zida et al., 2017), mainly focusing on triazoles (Cuenca-Estrella et al., 2004; González et al., 2009; Irfan et al., 2017; Park et al., 2004b; Sanglard and Coste, 2016), peptides (Dartevelle et al., 2018; do Nascimento Dias et al., 2020; Lum et al., 2015; Ramamourthy et al., 2020; Wang et al., 2015), and plant compounds (Bernardes et al., 2012; Bona et al., 2016; Chen et al., 2013; D'Auria et al., 2005; Lemar et al., 2005; Patel and Coogan, 2008; Serra et al., 2018; Shai et al., 2008; Tampieri et al., 2005; Violante et al., 2012).

Plants that have been used as herbal medicines for a long time are relatively safe even when used as antifungal agents. Cynomorium coccineum has antifungal efficacy not only against $C$. albicans, but also against $C$. tropicalis, C. krusei, C. guilliermondii, C. parapsilosis, and C. neoformans (Gonçalves et al., 2015). Acetone extracts of Punica granatum L., Quercus suber L., and Vicia faba L. showed the minimum inhibitory concentration (MIC) at $0.090,0.105$, and $0.010 \mathrm{mg} / \mathrm{mL}$, respectively, for C. albicans (Akroum, 2017). However, natural plant extracts tend to be less effective than conventional chemical antifungal agents. The MIC ranges for $C$. albicans of fluconazole, amphotericin B, voriconazole, and caspofungin were reported to be $0.25-32,0.03-0.25$, $0.03-0.25$, and $0.015-0.25 \mu \mathrm{g} / \mathrm{mL}$, respectively (Eksi et al., 2013). The MIC values of ethanol extracts of the plants Trachyspermum ammi, Teucrium polium, Piper nigrum, Pistachia vera, and Camelia sinensis were between 6.25 and $25 \mathrm{mg} / \mathrm{mL}$ (Masomi and Hassanshahian, 2016). Meanwhile, the MIC values of alcoholic extracts of the plants Lawsania inermis, Portulaca oleracea, Salvadora persica, and Asphodelus tenuifolius were between 10 and $50 \mu \mathrm{g} / \mathrm{mL}$ (Soliman et al., 2017). Recently, the antifungal activity of Cinnamomum loureirii Nees (Lee et al., 2021) and C. parthenoxylon (Adfa et al., 2020) has also been reported. In addition to plants, the fungi, Pestalotiopsis theae and Curvularia sp., also produced antifungal chemicals (Hidayat et al., 2019). Antifungal activity derived from natural products provides an eco-friendly method for inhibiting mold (Ham et al., 2021; Hidayat et al., 2019; Jung, 2019; Suprapti et al., 2020; Yun et al., 2021) that causes wood deterioration.

In order to effectively use the antifungal activity, many studies have been conducted to show synergistic antifungal activity by mixing the compounds. The antifungal efficacy of D-penicillamine increased against $C$. albicans by mixing with fluconazole (Li et al., 2019). As plant extracts, a synergistic antifungal effect against C. albicans and Aspergillus niger was reported by mixing clove, cumin and caraway essential oils or by mixing their major active components (Hassan et al., 2020).

Phellodendron amurense grows in China, Korea, Japan, Vietnam, and eastern Russia. Its bark, Phellodendri Cortex, has been used for treating meningitis, cirrhosis, 
dysentery, pneumonia, and tuberculosis (Ryuk et al., 2012; Sun et al., 2019). In recent studies, Phellodendri Cortex was shown to have anti-inflammatory (Fujii et al., 2017), anti-viral (Kim et al., 2016), anti-diarrhea (Xu et al., 2020), neuroprotective (Xian et al., 2013), and anti-diabetic activities (Tian et al., 2020).

Magnolia officinalis is a large tree found in central China, the bark (Magnoliae Cortex) of which has been used as a medicine for treating abdominal swelling and anxiety in East Asia and Southeast Asia for more than 2,000 years (Luo et al., 2019). Pharmacological studies have indicated that Magnoliae Cortex has a wide range of therapeutic effects, including antimicrobial (Chan et al., 2008), anticancer (Saito et al., 2009), analgesic (Luo et al., 2019), anti-inflammatory (Ni et al., 2020), and antioxidant activities (Chan et al., 2008; Luo et al., 2019). Moreover, Magnoliae Cortex and Phellodendri Cortex have been reported to have antifungal efficacy against C. albicans (Chan et al., 2008; Park et al., 1999). In this study, we propose a synergistic treatment by mixing two extracts that achieves higher antifungal efficacy at a lower dose. Combination therapy has the advantage of increasing the antifungal efficacy, enabling the treatment of infections with antifungal-resistant strains, reducing the emergence of resistant strains, and minimizing side effects by reducing the dose of agents (Baddley and Pappas, 2005). However, there have been few studies on synergistic antifungal activities between plant extracts. In this study, the synergistic efficacy of antifungal activity by mixing Magnoliae Cortex and Phellodendri Cortex extracts, which are strong antifungal active extracts discovered from the extract library (Yoon and Kim, 2021), was evaluated.

\section{MATERIALS and METHODS}

\subsection{Candida albicans and chemicals}

C. albicans KCTC 7965 was purchased from Korean
Collection for Type Cultures in the Korea Research Institute of Bioscience and Biotechnology (Jeongeup, Korea) and stored at $-80^{\circ} \mathrm{C}$ with $15 \%$ glycerol.

Phellodendri Cortex and Magnoliae Cortex were purchased from Jiundang Oriental Pharmacy (Seoul, Korea). RPMI 1640 (catalog number: R6604-10X1L) and MOPS[3-(N-morpholino)propanesulfonic acid] (catalog number: M1254-250G) were purchased from SigmaAldrich (Seoul, Korea). Tween 20 (catalog number: 6571-1405) and sodium hydroxide (catalog number: 7571-4400) were purchased from Daejung Chemicals \& Metals (Siheung, Korea). Sodium chloride (catalog number: S0476) and dimethyl sulfoxide (DMSO) were purchased from Samjeon Chemical (Seoul, Korea), and Duksan Pharmaceutical (Ansan, Korea), respectively. Berberine (catalog number: B0451) and magnolol (catalog number: D3971) were purchased from Tokyo Chemical Industry (Tokyo, Japan). Amphotericin B (catalog number: J61491.MC) was purchased from Fisher Scientific Korea (Seoul, Korea).

\subsection{Preparing extracts of Magnoliae Cortex and Phellodendri Cortex}

For the water extracts, the herbal plants were minced into pieces of $1 \mathrm{~mm}$ or less, $10 \mathrm{~g}$ of which was immersed in $100 \mathrm{~mL}$ of distilled water. Extraction was performed at $100^{\circ} \mathrm{C}$ for $4.5 \mathrm{~h}$ using a reflux extractor (EP1010-250P; Labdia, Seoul, Korea), and the solid content was removed by filtration using Whatman ${ }^{\circledR}$ Qualitative Filter Paper (Grade 1; GE Healthcare Life Science, Seoul, Korea). The filtered extract was dried using a freeze dryer (FDU-1200; Sunileyela Co., Ltd., Seongnam, Korea) after the removal of water in a rotary evaporator (RV 10 digital V, catalog number: 00100047 99; $\mathrm{IKA}^{\circledR}$ Korea, Seoul, Korea) at $90^{\circ} \mathrm{C}$.

For the ethanol extracts, the herbal plants were minced into pieces of $5 \mathrm{~cm}$ or less, $30 \mathrm{~g}$ of which was immersed in $300 \mathrm{~mL}$ of $95 \%$ ethanol. The plants were 
extracted at $50^{\circ} \mathrm{C}$ in a water bath for $3 \mathrm{~h}$. After extraction, the solid particles were removed using Whatman ${ }^{\circledR}$ Qualitative Filter Paper (Grade 1, catalog number: 10010155; GE Healthcare Life Science). The extracts were concentrated at $50^{\circ} \mathrm{C}$ using a rotary evaporator (RV 10 digital V; IKA ${ }^{\circledR}$ Korea) and dried in a dryer at $60^{\circ} \mathrm{C}$ for 2 weeks.

For the carbon dioxide supercritical extraction, Phellodendri Cortex and Magnoliae Cortex were purchased from Sunil Herb (Hongcheon, Korea). Each extract was produced by EnSNature (Anseong, Korea). Phellodendri Cortex (3,290 g) and Magnoliae Cortex (3,200 g) were added to a $10 \mathrm{~L}$ supercritical extractor, and extracted for 6 and 5 h, respectively, using supercritical carbon dioxide at 350 bar and $50^{\circ} \mathrm{C}$. Impurities were removed using Whatman ${ }^{\circledR}$ Qualitative Filter Paper (Grade 4; GE Healthcare Life Science).

\subsection{The culture conditions for Candida albicans}

C. albicans was cultured according to previous studies (Yoon and Kim, 2021). A Sabouraud's dextrose (SD) agar plate was prepared by adding $1.5 \% \mathrm{w} / \mathrm{v}$ agar (catalog number: 214010, BD Biosciences Korea, Seoul, Korea) to $3 \% \mathrm{w} / \mathrm{v}$ SD broth (catalog number: 238230 , BD Biosciences Korea). C. albicans was streaked on SD agar plates and incubated at $35^{\circ} \mathrm{C}$ for 1 day twice in order to obtain a single colony before cultures. RPMI 1640 medium was prepared with $0.165 \mathrm{~mol} / \mathrm{L} \mathrm{MOPS}$, and the $\mathrm{pH}$ was adjusted to 7.0 with $1 \mathrm{M}$ sodium hydroxide.

\subsection{Evaluation of antifungal activity}

Antifungal activity of samples was evaluated according to the CLSI M27-A2 method (Pfaller et al., 2008a). Phellodendri Cortex water extract (PC-WE) was dissolved in RPMI 1640 medium to a concentration of $50 \mathrm{~g} / \mathrm{L}$ and then centrifuged at $11,400 \times \mathrm{g}$ for $10 \mathrm{~min}$ to remove undissolved solids. Magnoliae Cortex carbon dioxide supercritical extract (MC-CDSE) was dissolved in RPMI 1640 medium with $50 \% \mathrm{v} / \mathrm{v}$ of Tween 20 to a concentration of $100 \mathrm{~g} / \mathrm{L}$ and then centrifuged at $11,400 \times \mathrm{g}$ for $10 \mathrm{~min}$ to remove undissolved solids. Berberine and magnolol were dissolved in DMSO to concentrations of 80 and $75.09 \mathrm{mM}$, respectively.

To evaluate the antifungal effect, PC-WE was diluted 5 times with RPMI 1640 medium, and then diluted 2 times sequentially with RPMI 1640 medium. MC-CDSE was diluted 50 times with RPMI 1640 medium, and then diluted 2 times sequentially with RPMI 1640 medium and $1 \%$ Tween 20. Berberine and magnolol were diluted 50 times with RPMI 1640 medium, and then diluted twice sequentially with RPMI 1640 medium and 2\% v/v DMSO.

One hundred microliters of the prepared sample were dispensed into a Corning ${ }^{\circledR}$ 96-well Clear Round Bottom Polystyrene Not Treated Microplate (catalog number: 3788; Corning, New York, NY, USA). As a solvent control, RPMI 1640 medium for PC-WE test, RPMI 1640 medium with $0.5 \%$ Tween 20 for MC-CDSE test, and RPMI 1640 medium with 1\% DMSO for berberine and magnolol test were used. To measure the absorbance of the sample itself in the medium, $100 \mu \mathrm{L}$ of the corresponding medium was dispensed in the wells instead of $100 \mu \mathrm{L}$ of the bacterial inoculation.

C. albicans from a single colony was suspended in $0.145 \mathrm{~mol} / \mathrm{L}$ sodium chloride and vortexed for $15 \mathrm{~s}$. The absorbance of the suspension was measured at $530 \mathrm{~nm}$ using an Optizen 2120 UV Plus spectrophotometer (Mecasys, Daejeon, Korea), and the cell concentration was adjusted to $0.5 \mathrm{McFarland}$ standard. The prepared cell suspension was diluted 1,000-fold with RPMI 1640 medium, so that the cell concentration was $1 \times 10^{3}$ to $5 \times 10^{3} \mathrm{CFU} / \mathrm{mL}$. One hundred microliters of the diluted cell suspension was dispensed into wells and incubated at $35^{\circ} \mathrm{C}$ for $48 \mathrm{~h}$. The cell density was measured by the 
absorbance at $540 \mathrm{~nm}$ using a Synergy ${ }^{\mathrm{TM}}$ LX MultiMode Reader (BioTek Instruments Korea, Seoul, Korea).

\subsection{Evaluation of synergistic antifungal activity}

Synergistic antifungal activity was evaluated by microdilution checkerboard assay (Sun et al., 2009). The sample was prepared in the same manner as described in the above section "Evaluation of antifungal activity" with dilution with RPMI 1640 medium to four times higher than the final treatment concentration. The synergistic antifungal activity of sample mixture was measured using Corning ${ }^{\circledR}$ 96-well Clear Round Bottom Polystyrene Not Treated Microplate (product number: 3788; Corning) with $50 \mu \mathrm{L}$ of each diluted sample. $C$. albicans cells were inoculated and incubated in accordance with the CLSI M27-A2 method in the same manner as described in the above section "Evaluation of antifungal activity". The cell density was measured by the absorbance at $540 \mathrm{~nm}$ using a Synergy ${ }^{\mathrm{TM}} \mathrm{LX}$ Multi-Mode Reader (BioTek Instruments Korea, Seoul, Korea).

The antifungal activity was expressed as relative growth inhibition ( $\mathrm{GI}_{\text {sample }}$ ), which was calculated as the decrease in cell concentration $\left(\mathrm{OD}_{\text {sample }}\right)$ of the sample relative to the cell concentration $\left(\mathrm{OD}_{\text {control }}\right)$ of the untreated control group.

$$
\mathrm{GI}_{\text {sample }}=\left(\mathrm{OD}_{\text {control }}-\mathrm{OD}_{\text {sample }}\right) / \mathrm{OD}_{\text {control }} \times 100
$$

When the $\mathrm{GI}_{\mathrm{A}+\mathrm{B}}$ of the mixture of two samples was more than twice the $\mathrm{GI}_{\mathrm{A}}$ of one sample and the $\mathrm{GI}_{\mathrm{B}}$ of the other sample, it was judged as evidence of synergistic antifungal activity.

Synergistic antifungal activity:

$$
2 \leq \mathrm{GI}_{\mathrm{A}+\mathrm{B}} / \mathrm{GI}_{\mathrm{A}} \text { and } \mathrm{GI}_{\mathrm{A}+\mathrm{B}} / \mathrm{GI}_{\mathrm{B}}
$$

\subsection{Quantitative analysis of berberine and magnolol in extracts using high- performance liquid chromatography}

The levels of berberine and magnolol in extracts were analyzed by high-performance liquid chromatography, using the instrument used in a previous study (Yoon and Kim, 2021) with YMC-Triart C18 (catalog number: TA12S05-2546WT; YMC Korea, Seongnam, Korea) as the analytical column. The operating conditions for the analyses of both berberine and magnolol were similar to those in a previous study (Kim and Kim, 2004), with minor modifications.

The mobile phase used for berberine analysis was a solution of wateracetonitrile $=1: 1(\mathrm{v}: \mathrm{v})$ with $3.4 \mathrm{~g} / \mathrm{L}$ potassium dihydrogenphosphate and $1.7 \mathrm{~g} / \mathrm{L}$ sodium lauryl sulfate. Analysis was performed under isocratic conditions with a flow rate of $1 \mathrm{~mL} / \mathrm{min}$, detection of berberine using absorbance at $345 \mathrm{~nm}$, column temperature of $40^{\circ} \mathrm{C}$, and total analysis time of $60 \mathrm{~min}$.

When analyzing magnolol, the mobile phase was a solution of acetonitrile: $2 \%$ acetic acid $=1: 1$ under isocratic conditions with a flow rate of $1 \mathrm{~mL} / \mathrm{min}$. Magnolol was detected using absorbance at $289 \mathrm{~nm}$, column temperature of $30^{\circ} \mathrm{C}$, and total analysis time of $60 \mathrm{~min}$.

\subsection{Measuring DNA released by cell destruction}

The disruption of cell integrity was evaluated by measuring the extracellular DNA concentration, following a slightly modified version of a process used in previous studies (Bennis et al., 2004; Rajkowska et al., 2016; Zorić et al., 2017). Phosphate-buffered saline (PBS) solution was prepared by dissolving $8 \mathrm{~g}$ of sodium chloride, $0.2 \mathrm{~g}$ of potassium chloride, $1.44 \mathrm{~g}$ of disodium phosphate, and $0.24 \mathrm{~g}$ of potassium dihydrogen phosphate in $1 \mathrm{~L}$ of distilled water. The $\mathrm{pH}$ of the 
PBS solution was adjusted to 7.4 using hydrogen chloride.

A suspension of $C$. albicans cells having $1 \times 10^{3}$ to $5 \times 10^{3} \mathrm{CFU} / \mathrm{mL}$ was prepared in the same manner as described in the above section "Evaluation of antifungal activity". The cell suspension $(10 \mathrm{~mL})$ was dispensed into a $250 \mathrm{~mL}$ baffled flask with an additional $10 \mathrm{~mL}$ of RPMI 1640 medium, and cultured at $35^{\circ} \mathrm{C}$ for $48 \mathrm{~h}$ without shaking. Berberine (0.62 mM), magnolol (0.41 $\mathrm{mM})$, and amphotericin $\mathrm{B}(6.49 \mu \mathrm{M})$ were prepared in PBS solution with 2\% DMSO.

Berberine (80 mM), magnolol $(75.09 \mathrm{mM})$, and amphotericin B (32.46 mM) were dissolved in DMSO, diluted 50 times with PBS first, and further diluted with PBS containing 2\% DMSO to obtain a final treatment concentration.

The culture medium was diluted with RPMI 1640 medium so that the absorbance at $530 \mathrm{~nm}$ was 0.5 , and aliquoted at $200 \mu \mathrm{L}$ into a Corning ${ }^{\circledR}$ 96-well Clear Round Bottom Polystyrene Not Treated Microplate (product number: 3788; Corning). The plate was centrifuged at $840 \times \mathrm{g}$ for $15 \mathrm{~min}$ at room temperature and the supernatant was removed. To the cell pellet, $50 \mu \mathrm{L}$ of solution was added per sample, and PBS was added to make up the volume to $200 \mu \mathrm{L}$. In the positive and negative controls, $100 \mu \mathrm{L}$ of solution was added to the cell pellet, and PBS was added to make up the volume to $200 \mu \mathrm{L}$. The plate was incubated for $24 \mathrm{~h}$ at $35^{\circ} \mathrm{C}$ and centrifuged at $840 \times \mathrm{g}$ for $15 \mathrm{~min}$. The amount of extracellularly released DNA in the supernatant was measured using absorbance at $260 \mathrm{~nm}$.

\subsection{Measuring ergosterol binding}

Ergosterol was purchased from Tokyo Chemical Industry (catalog number: E0018). Ergosterol binding assay was performed to determine whether compounds directly bind to ergosterol in C. albicans cell membranes to clarify whether it causes cell membrane destruction.
The ergosterol binding assay was performed following a slightly modified version of a previously reported procedure (Escalante et al., 2008; Leite et al., 2014a). Berberine, magnolol, amphotericin $\mathrm{B}$, and ergosterol were dissolved in DMSO and diluted with RPMI 1640 medium. One hundred microliters of sample were dispensed into a Corning ${ }^{\circledR}$ 96-well Clear Round Bottom Polystyrene Not Treated Microplate, and C. albicans was inoculated and incubated in the same manner as described in the above section "Evaluation of antifungal activity".

\subsection{Quantitative analysis of ergosterol in C. albicans}

Quantitative analysis of ergosterol was used here as a method to measure the change in ergosterol production in $C$. albicans according to the sample treatment, following a partially modified version of a previously described method (Arthington-Skaggs et al., 1999).

Berberine, magnolol, and fluconazole were dissolved with RPMI 1640 medium with 2\% DMSO. Five milliliters of sample solution were added to a $250 \mathrm{~mL}$ flask and RPMI 1640 medium with 2\% DMSO was added to make the volume up to $10 \mathrm{~mL}$. A cell suspension of $C$. albicans having $1 \times 10^{3}$ to $5 \times 10^{3} \mathrm{CFU} / \mathrm{mL}$ was prepared as described in the above section "Evaluation of antifungal activity". Ten milliliters of prepared cell suspension were added to the flask and incubated at $35^{\circ} \mathrm{C}$ for 2 days without shaking. The cell pellet was collected by centrifugation at $680 \times \mathrm{g}$ for $5 \mathrm{~min}$, washed with PBS solution ( $\mathrm{pH} 7.4$ ), and weighed. Three milliliters of $25 \%$ alcoholic potassium hydroxide solution $(25 \mathrm{~g}$ of potassium hydroxide, $35 \mathrm{~mL}$ of distilled water, $100 \%$ ethanol added to make up the volume to $100 \mathrm{~mL}$ ) was added and mixed well. The cell suspension was transferred to a sterilized glass tube and incubated in a water bath at $85^{\circ} \mathrm{C}$ for $1 \mathrm{~h}$. After adding $1 \mathrm{~mL}$ of distilled water and $3 \mathrm{~mL}$ of $\mathrm{n}$-heptane to the cooled cell suspension, sterol 
was extracted by mixing for $3 \mathrm{~min}$. The $\mathrm{n}$-heptane layer was transferred to a clean glass tube and diluted with $100 \%$ ethanol, if necessary, to measure the absorbance at $281.5 \mathrm{~nm}$ and $230 \mathrm{~nm}$. The ergosterol concentration was calculated in accordance with a previously reported method (Arthington-Skaggs et al., 1999) using these absorbance values.

\subsection{Statistical analysis}

Statistical analysis was performed using SPSS Statistics ver. 25 (IBM Korea, Seoul, Korea). The statistical significance of differences was tested by one-way analysis of variance (ANOVA) using Tukey's method. Statistical analysis was performed by comparing the values of the negative control group to which no sample was added with those of the experimental groups treated with sample.

\section{RESULTS and DISCUSSION}

\subsection{Extraction method for antifungal efficacy of Phellodendri Cortex and Magnoliae Cortex against C. albicans}

A previous study revealed the antifungal activities of the methanol extract of Phellodendri Cortex and Magnoliae Cortex against C. albicans (Yoon and Kim, 2021). To determine a suitable extraction method enabling these effects to be applied to the human body, three extraction methods, using ethanol, hot water, and supercritical carbon dioxide, were used to extract Phellodendri Cortex and Magnoliae Cortex. Although the growth of $C$. albicans was completely inhibited with all three solvent extracts of Magnoliae Cortex at $1 \mathrm{~g} / \mathrm{L}$, a supercritical carbon dioxide extract was selected for the subsequent experiment considering the highest concentration of $36 \%$ magnolol, the active compound of Magnoliae Cortex. In the case of Phellodendri Cortex, the hot water extraction method was selected based on cell growth inhibitory activity, extraction yield, and the highest concentration of $2.4 \%$ berberine, a candidate active compound in Phellodendri Cortex.

Zazharskyi et al. (2020) evaluated the antimicrobial activity of 38 plant extracts by a disk diffusion method. Among the tested extracts, $70 \%$ ethanol extract of the sprouts and leaves of Phellodendron amurense Rupr. showed antifungal activity against $C$. albicans via the formation of a clear region of $8.7 \pm 0.7 \mathrm{~mm}$ around the disk. In addition, the screening of antifungal activity with a disk diffusion method using a library of 226 plant extracts in another study (Min et al., 1996) showed that the diethyl ether extract and methanol extract of Phellodendri Cortex exerted antifungal activity against $C$. albicans with a clear ring of $10 \mathrm{~mm}$.

Chan et al. (2008) tested the antimicrobial activity of extracts made with eight plants including Magnoliae Cortex. In the disk diffusion method using $100 \mu \mathrm{g}$ of extract, hot water extract or methanol extract did not show any antifungal effect on C. albicans, but ethanol extract of Magnoliae Cortex showed a clear ring 0.89 times the size of that of chlorhexidine used as an antifungal standard. It is suggested that the discrepancy between the results of this study and Chan's results (Chan et al., 2008) on the antifungal activity of methanol extract on C. albicans is due to the difference in the amount of extract tested.

\subsection{Synergistic antifungal effects of Phellodendri Cortex water extract and Magnoliae Cortex supercritical extract against $C$. albicans}

The antifungal activity against $C$. albicans according to extract concentration was measured using the hot water extract of Phellodendri Cortex (PC-WE) and the carbon dioxide supercritical extract of Magnoliae Cortex (MC-CDSE) (Fig. 1). The antifungal activity of PC-WE increased rapidly as the concentration of the extract increased, and showed antifungal activity of about $80 \%$ 


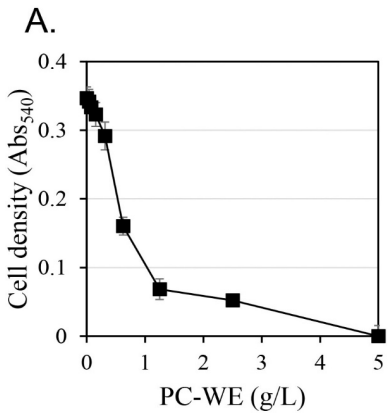

B.

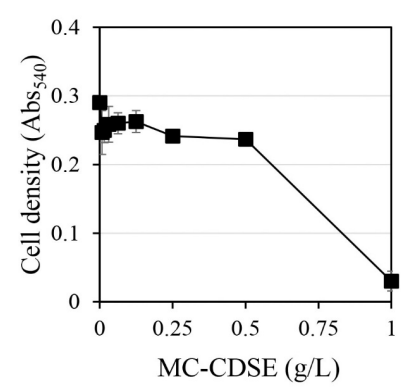

Fig. 1. Antifungal activity of (A) the hot water extract of Phellodendri Cortex (PC-WE) and (B) the carbon dioxide supercritical extract of Magnoliae Cortex (MC-CDSE) against Candida albicans.

at $1.25 \mathrm{~g} / \mathrm{L}$. At concentrations above $1.25 \mathrm{~g} / \mathrm{L}$, the antifungal activity gradually increased with increasing concentration of the extract, and the antifungal activity was almost $100 \%$ at $5 \mathrm{~g} / \mathrm{L}$. MC-CDSE showed little antifungal activity up to $0.5 \mathrm{~g} / \mathrm{L}$, but about $90 \%$ antifungal activity at $1 \mathrm{~g} / \mathrm{L}$.

The synergistic antifungal activity against $C$. albicans upon mixing MC-CDSE and PC-WE was evaluated (Fig. 2). If the antifungal activity of mixtures was twice or more in both cases compared with the antifungal effect when each single extract was administered, it was judged that synergistic activity occurred. Synergistic antifungal activities were observed when the concentration of MCCDSE was $0.59 \mathrm{~g} / \mathrm{L}$ and the concentration of PC-WE was $0.55 \mathrm{~g} / \mathrm{L}$. MC-CDSE only had antifungal activity of $9.6 \%$ at $0.59 \mathrm{~g} / \mathrm{L}$, and PC-WE only had antifungal

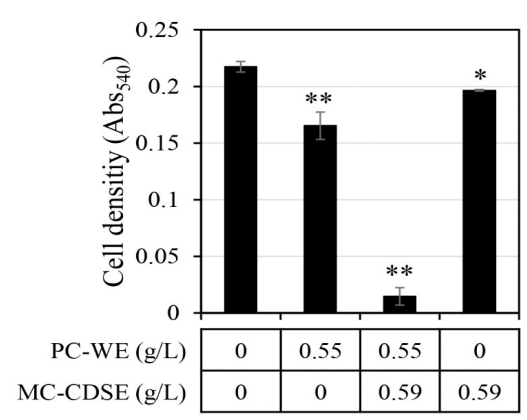

Fig. 2. Antifungal synergistic activity of the combination of hot water extract of Phellodendri Cortex (PC-WE) and carbon dioxide supercritical extract of Magnoliae Cortex (MC-CDSE) against Candida albicans. Statistical analysis was performed using paired $t$-tests. Values that differ from the control at $95 \%$ and $99 \%$ confidence levels are marked with one and two asterisks, respectively, on the top of the bars.

activity of $24 \%$ at $0.55 \mathrm{~g} / \mathrm{L}$, but the mixture of these two extracts at the same concentration showed an antifungal effect of $93.3 \%$.

\subsection{Antifungal compounds, berberine and magnolol, from Phellodendri Cortex and Magnoliae Cortex, respectively}

Alkaloid compounds in Phellodendri Cortex were reported to exhibit antifungal activities (Campos et al., 2018; Kim et al., 2018; Sun et al., 2019; Xie et al., 2020). The major compound among alkaloids in the extract of Phellodendri Cortex was shown to be berberine (Chan et al., 2007). Berberine is known to have antimicrobial (Čerňáková and Koštálová, 2002; Freile et al., 2003), anti-inflammatory (Kuo et al., 2004), anticancer (Kumar et al., 2015), and antioxidant activities (Kumar et al., 2015). It has also been reported to exhibit antifungal activity against $C$. albicans by disrupting the cell membrane (Zhao et al., 2010; Zorić et al., 2017).

The level of berberine in the extracts of Phellodendri Cortex was analyzed using high-performance liquid 
chromatography. Berberine was found in hot water extract at $2.4 \% \mathrm{w} / \mathrm{w}$ but not in carbon dioxide supercritical extract of Phellodendri Cortex in this study. The level of berberine ranged between $0.515 \% \mathrm{w} / \mathrm{w}$ and $7.425 \% \mathrm{w} / \mathrm{w}$ depending on the batch when pulverized Phellodendri Cortex was extracted with methanol containing $1 \% \mathrm{HCl}$ in a previous study (Zhu et al., 2011). Although the extraction solvent differed, the berberine concentration of PC-WE produced in this experiment fell within that previously reported concentration range (Zhu et al., 2011).

Magnolol is a polyphenolic compound that is mainly isolated from Magnoliae Cortex and has anti-inflammatory (Park et al., 2004a; Shen et al., 2018), antimicrobial (Park et al., 2004a), antioxidant (Parray et al., 2018), and anticancer activities (Cheng et al., 2016). Magnolol is also widely known to have antifungal activity, including against $C$. albicans, by destroying the cell membrane (Behbehani et al., 2017; Chen et al., 2019; Oufensou et al., 2019; Sun et al., 2015a; Zhou et al., 2017).

In the analysis of magnolol in the Magnoliae Cortex extract, it was hardly observed in the hot water extract, but the proportion of magnolol in the carbon dioxide supercritical extract was $36.1 \% \mathrm{w} / \mathrm{w}$. The amount of Magnoliae Cortex used for MC-CDSE was 3,200 g, and the mass of MC-CDSE was $55 \mathrm{~g}$. The solid yield of the extract was $1.72 \%$. The amount of magnolol in MCCDSE from 3,200 $\mathrm{g}$ of Magnoliae Cortex was $20 \mathrm{~g}$ in this study. Considering that the magnolol content in Magnoliae Cortex is $0.33 \%-0.75 \% \mathrm{w} / \mathrm{w}$ (Chen et al., 2006; Tsai and Chen, 1992), the $0.62 \% \mathrm{w} / \mathrm{w}$ magnolol extraction yield in this study was quite high. According to a study by Jiang et al. (2012), the concentration of magnolol in the methanol extract using powdered Magnoliae Cortex ranged from $0.005 \% \mathrm{w} / \mathrm{w}$ to $9.191 \% \mathrm{w} / \mathrm{w}$. The magnolol concentration $(36.1 \% \mathrm{w} / \mathrm{w})$ of the MCCDSE in this study was about 3.9 times higher than the maximum concentration $(9.191 \% \mathrm{w} / \mathrm{w})$ in a previous study (Jiang et al., 2012). Considering this extraction yield and the high magnolol content of the extract, it was suggested that the carbon dioxide supercritical extraction method was suitable for extracting magnolol for antifungal activity from Magnoliae Cortex.

\subsection{Synergistic antifungal efficacy of berberine and magnolol against C. albicans}

Since berberine and magnolol had antifungal activity against $C$. albicans and contributed a significant part of the extracts of Phellodendri Cortex and Magnoliae Cortex, respectively, studying the synergistic antifungal efficacy of berberine and magnolol against $C$. albicans should provide a clue to understand the synergistic antifungal efficacy of Phellodendri Cortex and Magnoliae Cortex.

First, the antifungal efficacy of berberine and magnolol was quantitatively analyzed (Fig. 3). Berberine rapidly increased antifungal activity in proportion to the concentration up to $200 \mu \mathrm{M}$, showing around $80 \%$ growth inhibitory activity at $200 \mu \mathrm{M}$, but gradually increased its antifungal activity thereafter at concentrations higher than $200 \mu \mathrm{M}$, showing almost $100 \%$ growth inhibitory activity at $400 \mu \mathrm{M}$ ( $\boldsymbol{\Delta}$ in Fig. 3B). In the case of magnolol, the antifungal activity increased in proportion to the concentration, and growth inhibition was almost $100 \%$ at $370 \mu \mathrm{M}$ ( $\boldsymbol{\Delta}$ in Fig. $3 \mathrm{C}$ ). Based on the antifungal activities of berberine and magnolol as shown in Fig. 3, the synergistic antifungal activity was evaluated at the concentrations of $160 \mu \mathrm{M}$ for berberine and 100 $\mu \mathrm{M}$ for magnolol (Fig. 4). Although $160 \mu \mathrm{M}$ berberine showed $24.0 \%$ growth inhibition and $100 \mu \mathrm{M}$ magnolol showed $25.9 \%$ growth inhibition, their combination at the same concentrations inhibited $C$. albicans growth by $77.1 \%$. The growth inhibitory activity by the combination of these two compounds increased about three times compared with the activity upon administering each compound alone, so growth was synergistically inhibited. 
A.

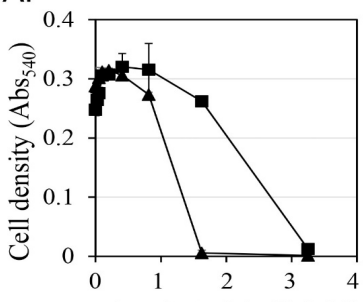

B. Amphotericin B $(\mu \mathrm{M})$

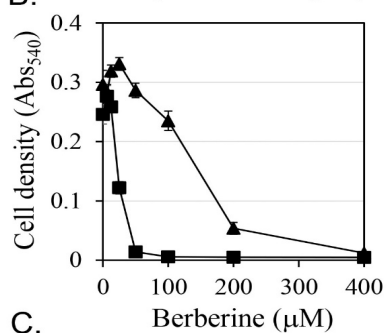

C.

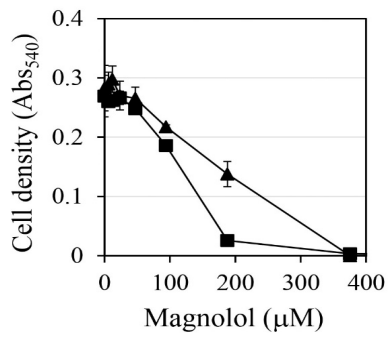

Fig. 3. Changes in antifungal activity of (A) amphotericin B, (B) berberine, and (C) magnolol against Candida albicans upon ergosterol addition, $\boldsymbol{\Delta}$ : without $0.25 \mathrm{mM}$ ergosterol, $\mathbf{\square}$ : with $0.25 \mathrm{mM}$ ergosterol.

How much the antifungal activities of the mixture of berberine and magnolol contributed to the antifungal activities of the mixture of PC-WE and MC-CDSE was calculated. Since PC-WE contained $2.4 \%$ berberine, the concentration of $0.55 \mathrm{~g} / \mathrm{L}$ PC-WE tested as shown in Fig. 2, which showed $24.0 \%$ growth inhibition, contained $39 \mu \mathrm{M}$ berberine. As shown in Fig. 3B, berberine at 39 $\mu \mathrm{M}$ did not show any growth inhibitory activity. These results indicated that PC-WE contained other antifungal compounds such as palmatine in addition to berberine.

In the case of MC-CDSE, the content of magnolol was $36.1 \%$, so $0.59 \mathrm{~g} / \mathrm{L}$ MC-CDSE tested as shown in Fig. 2, which showed $9.6 \%$ growth inhibition, contained

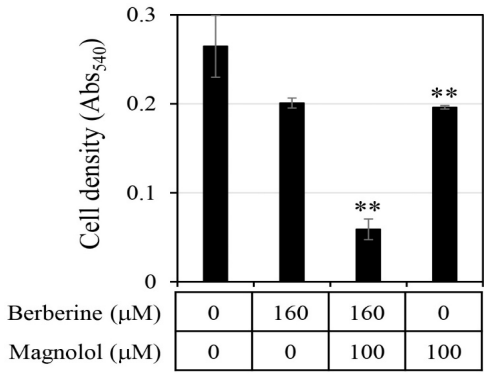

Fig. 4. Synergistic antifungal activity of the combination of berberine and magnolol against Candida albicans. Statistical analysis was performed using paired $t$-tests. Values that differ from the control at the $99 \%$ confidence level are marked with two asterisks on the top of the bars.

$800 \mu \mathrm{M}$ magnolol. The growth of $C$. albicans was completely inhibited at a concentration of $800 \mu \mathrm{M}$ (data not shown in Fig 3C). The low antifungal activity of MC-CDSE despite the high concentration of magnolol suggests the presence of compounds that interfere with the antifungal activity of magnolol in MC-CDSE.

\subsection{Antifungal mechanisms of berberine and magnolol compared to amphotericin B}

We investigated how berberine and magnolol inhibited the growth of $C$. albicans synergistically on the basis of previously reported antifungal mechanisms, releasing chromosomal DNA by cell destruction (Hammer et al., 2004; Rajkowska et al., 2016), inhibiting the synthesis of ergosterol (Arthington-Skaggs et al., 1999; Khan et al., 2013), and interfering with the antifungal activity by exogenous ergosterol (Lee and Kim, 2016; Miron et al., 2014).

The amount of chromosomal DNA released from $C$. albicans was measured by treatment with $160 \mu \mathrm{M}$ berberine and $100 \mu \mathrm{M}$ magnolol (Fig. 5). When berberine and magnolol were administered alone, absorbance at $260 \mathrm{~nm}$ for measuring DNA was 0.165 and 0.070 , res- 


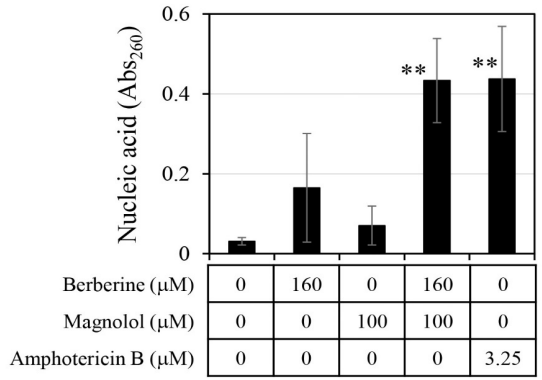

Fig. 5. Synergistic release of chromosomal DNA from Candida albicans by the combination of berberine and magnolol. Statistical analysis was performed using paired $t$-tests. Values that differ from the control with a $99 \%$ confidence level are marked with two asterisks on the top of the bars.

pectively, which were levels 5.3 times and 2.3 times higher than the negative control. This confirmed that berberine and magnolol inhibited the growth of $C$. albicans by destroying cell integrity, as shown in previous studies (Sun et al., 2015b; Zorić et al., 2017). When berberine and magnolol were mixed, the absorbance at $260 \mathrm{~nm}$ was 0.43 , which was 13.87 times higher than that of the negative control, and the degree of chromosomal DNA release was comparable to that of amphotericin B, an antifungal compound used as a positive control. The release of DNA by the mixture of berberine and magnolol was 2.63 times higher than that of berberine alone and 6.15 times higher than that of magnolol alone, suggesting the synergistic disruption of the integrity of $C$. albicans cells by mixing these two compounds.

The ergosterol level in the C. albicans cells was analyzed after treatment with antifungal agents (Fig. 6). When berberine or magnolol was administered alone, the intracellular ergosterol levels were $70.8 \mathrm{ppm}$ and $50.0 \mathrm{ppm}$, respectively, involving reductions by $25.0 \%$ and $47.0 \%$ compared with the negative control lacking any antifungal treatment. When berberine and magnolol were mixed, the level of ergosterol in cells was 35.6

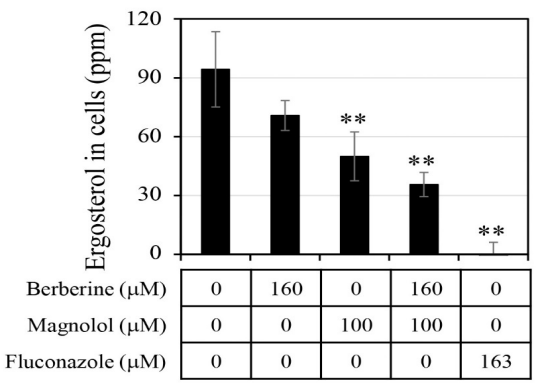

Fig. 6. Change in ergosterol content of Candida albicans by the combination of berberine and magnolol. Statistical analysis was performed using paired $t$-tests. Values that differ from the control at the $99 \%$ confidence level are marked with two asterisks on the top of the bars.

ppm, constituting a decrease in ergosterol production by $62.3 \%$ compared with the negative control. However, there was still significant ergosterol production upon treatment with the mixture of berberine and magnolol, compared with the level upon fluconazole treatment as a positive control. Although the level of ergosterol in cells upon mixing berberine and magnolol decreased more than that upon treatment with a single compound, it was an additive not synergistic effect. These results suggest that berberine and magnolol affected the synthesis of ergosterol, but this was not a significant biological mechanism for the synergistic antifungal activity.

If antifungal compounds inhibit cell growth in a way that interferes with the biological function of ergosterol, then additional ergosterol from outside of cells may restore cell growth. The effects of the addition of ergosterol on the antifungal activities of amphotericin B, berberine, and magnolol were evaluated (Fig. 3). Amphotericin $\mathrm{B}$ is known as an antifungal agent that binds to ergosterol and destroys the function of the membranes of fungal cells (Yamamoto et al., 2019). It has been reported that the antifungal activity of amphotericin B was reduced by the addition of ergosterol (Leite et al., 2014b; Miron et al., 2014). In this study, when 0.25 
$\mathrm{mM}$ ergosterol was added, it was observed that the antifungal activity of amphotericin B was reduced by about half (Fig. 3A). These results are consistent with the results of previous studies. In the case of berberine, the addition of $0.25 \mathrm{mM}$ ergosterol increased the antifungal activity by more than double (Fig. 3B), which is the opposite of the decrease in antifungal activity due to the addition of ergosterol in amphotericin B treatment. Magnolol also showed a tendency to enhance the antifungal activity upon the addition of $0.25 \mathrm{mM}$ ergosterol, but the degree of enhancement was smaller than that of berberine (Fig. 3C). The increase in antifungal activity against $C$. albicans upon the addition of ergosterol confirmed that the synergistic antifungal activity of the combination of berberine and magnolol was not associated with a decrease in the synthesis of ergosterol.

\section{CONCLUSION}

In this study, it was suggested that synergistic antifungal activity against $C$. albicans occurred through a combination of the hot water extract of Phellodendri Cortex and the carbon dioxide supercritical extract of Magnoliae Cortex. It was also suggested that berberine and magnolol were the active ingredients of each extract, respectively. Berberine and magnolol also showed a synergistic antifungal effect against C. albicans upon mixing.

The synergistic antifungal activity of the combination of berberine and magnolol was due to the destruction of the cell structure according to the findings on the release of chromosomal DNA, and was not correlated with inhibition of the biological function of ergosterol. Interestingly, the addition of extracellular ergosterol reduced the antifungal activity of amphotericin B, but in the case of berberine, the antifungal activity was increased by extracellular ergosterol. This suggested that the biological mechanism for the antifungal activity of berberine differed from that of amphotericin B, and it was sugges- ted that the extracellular ergosterol facilitated cell destruction by berberine.

\section{CONFLICT of INTEREST}

No potential conflict of interest relevant to this article was reported.

\section{ACKNOWLEDGMENT}

This study was carried out with the support of "R\&D Program for Forest Science Technology" (Project No. 2019150B10-2123-0301) provided by Korea Forest Service (Korea Forestry Promotion Institute).

\section{REFERENCES}

Adfa, M., Romayasa, A., Kusnanda, A.J., Avidlyandi, A., Yudha, S.S., Banon, C., Gustian, I. 2020. Chemical components, antitermite and antifungal activities of Cinnamomum parthenoxylon wood vinegar. Journal of the Korean Wood Science and Technology 48(1): 107-116.

Akroum, S. 2017. Antifungal activity of acetone extracts from Punica granatum L., Quercus suber L. and Vicia faba L. Journal de Mycologie Médicale 27(1): 83-89.

Arthington-Skaggs, B.A., Jradi, H., Desai, T., Morrison, C.J. 1999. Quantitation of ergosterol content: Novel method for determination of fluconazole susceptibility of Candida albicans. Journal of Clinical Microbiology 37(10): 3332-3337.

Baddley, J.W., Poppas, P.G. 2005. Antifungal combination therapy: Clinical potential. Drugs 65(11): 14611480.

Behbehani, J., Shreaz, S., Irshad, M., Karched, M. 2017. The natural compound magnolol affects growth, biofilm formation, and ultrastructure of oral Candida isolates. Microbial Pathogenesis 113: 209-217. 
Bennis, S., Chami, F., Chami, N., Bouchikhi, T., Remmal, A. 2004. Surface alteration of Saccharomyces cerevisiae induced by thymol and eugenol. Letters in Applied Microbiology 38(6): 454-458.

Bernardes, I., Felipe Rodrigues, M.P., Bacelli, G.K., Munin, E., Alves, L.P., Costa, M.S. 2012. Aloe vera extract reduces both growth and germ tube formation by Candida albicans. Mycoses 55(3): 257-261.

Bona, E., Cantamessa, S., Pavan, M., Novello, G., Massa, N., Rocchetti, A., Berta, G., Gamalero, E. 2016. Sensitivity of Candida albicans to essential oils: Are they an alternative to antifungal agents? Journal of Applied Microbiology 121(6): 1530-1545.

Brown, G.D., Denning, D.W., Gow, N.A.R., Levitz, S.M., Netea, M.G., White, T.C. 2012. Hidden killers: Human fungal infections. Science Translational Medicine 4(165): 165rv13.

Campos, R.S., Silva, C.R., Neto, J.B.A., Sampaio, L.S., Nascimento, F.B.S.A., Moraes, M.O., Cavalcanti, B.C., Magalhães, H.F., Gomes, A.O.C.V., Lobo, M.D.P., Júnior, H.V.N. 2018. Antifungal activity of palmatine against strains of Candida spp. resistant to azoles in planktonic cells and biofilm. International Journal of Current Microbiology and Applied Sciences 7(2): 3657-3669.

Čerňáková, M., Koštálová, D. 2002. Antimicrobial activity of berberine: A constituent of Mahonia aquifolium. Folia Microbiologica 47(4): 375-378.

Chan, C.O., Chu, C.C., Mok, D.K.W., Chau, F.T. 2007. Analysis of berberine and total alkaloid content in cortex phellodendri by near infrared spectroscopy (NIRS) compared with high-performance liquid chromatography coupled with ultra-visible spectrometric detection. Analytica Chimica Acta 592(2): 121-131.

Chan, L.W., Cheah, E.L.C., Saw, C.L.L., Weng, W., Heng, P.W.S. 2008. Antimicrobial and antioxidant activities of Cortex Magnoliae Officinalis and some other medicinal plants commonly used in South-
East Asia. Chinese Medicine 3(1): 15.

Chen, G., Xu, X., Zhu, Y., Zhang, L., Yang, P. 2006. Determination of honokiol and magnolol in Cortex Magnoliae Officinalis by capillary electrophoresis with electrochemical detection. Journal of Pharmaceutical and Biomedical Analysis 41(4): 1479-1484.

Chen, Y., Zeng, H., Tian, J., Ban, X., Ma, B., Wang, Y. 2013. Antifungal mechanism of essential oil from Anethum graveolens seeds against Candida albicans. Journal of Medical Microbiology 62(8): 1175-1183.

Chen, Y.H., Lu, M.H., Guo, D.S., Zhai, Y.Y., Miao, D., Yue, J.Y., Yuan, C.H., Zhao, M.M., An, D.R. 2019. Antifungal effect of magnolol and honokiol from Magnolia officinalis on Alternaria alternata causing tobacco brown spot. Molecules 24(11): 2140.

Cheng, Y.C., Hueng, D.Y., Huang, H.Y., Chen, J.Y., Chen, Y. 2016. Magnolol and honokiol exert a synergistic anti-tumor effect through autophagy and apoptosis in human glioblastomas. Oncotarget 7(20): 29116-29130.

Cuenca-Estrella, M., Gomez-Lopez, A., Mellado, E., Garcia-Effron, G., Rodriguez-Tudela, J.L. 2004. In vitro activities of ravuconazole and four other antifungal agents against fluconazole-resistant or -susceptible clinical yeast isolates. Antimicrobial Agents and Chemotherapy 48(8): 3107-3111.

D'Auria, F.D., Tecca, M., Strippoli, V., Salvatore, G., Battinelli, L., Mazzanti, G. 2005. Antifungal activity of Lavandula angustifolia essential oil against Candida albicans yeast and mycelial form. Medical Mycology 43(5): 391-396.

Dartevelle, P., Ehlinger, C., Zaet, A., Boehler, C., Rabineau, M., Westermann, B., Strub, J.M., Cianferani, S., Haïkel, Y., Metz-Boutigue, M.H., Marban, C. 2018. D-Cateslytin: A new antifungal agent for the treatment of oral Candida albicans associated infections. Scientific Reports 8(1): 9235.

de Oliveira Santos, G.C., Vasconcelos, C.C., Lopes, A.J.O., de Sousa Cartágenes, M.S., Filho, A.K.D.B., 
do Nascimento, F.R.F., Ramos, R.M., Pires, E.R.R.B., de Andrade, M.S., Rocha, F.M.G., de Andrade Monteiro, C. 2018. Candida infections and therapeutic strategies: Mechanisms of action for traditional and alternative agents. Frontiers in Microbiology 9: 1351.

do Nascimento Dias, J., de Souza Silva, C., de Araújo, A.R., Souza, J.M.T., de Holanda Veloso Júnior, P.H., Cabral, W.F., da Glória da Silva, M., Eaton, P., de Souza de Almeida Leite, J.R., Nicola, A.M., Albuquerque, P., Silva-Pereira, I. 2020. Mechanisms of action of antimicrobial peptides ToAP2 and NDBP-5.7 against Candida albicans planktonic and biofilm cells. Scientific Reports 10(1): 10327.

Eksi, F., Gayyurhan, E.D., Balci, I. 2013. In vitro susceptibility of Candida species to four antifungal agents assessed by the reference broth microdilution method. The Scientific World Journal 2013: 236903.

Enoch, D.A., Ludlam, H.A., Brown, N.M. 2006. Invasive fungal infections: A review of epidemiology and management options. Journal of Medical Microbiology 55(7): 809-818.

Escalante, A., Gattuso, M., Pérez, P., Zacchino, S. 2008. Evidence for the mechanism of action of the antifungal phytolaccoside B isolated from Phytolacca tetramera Hauman. Journal of Natural Products 71(10): 1720-1725.

Espinel-Ingroff, A., Pfaller, M.A., Bustamante, B., Canton, E., Fothergill, A., Fuller, J., Gonzalez, G.M., Lass-Flörl, C., Lockhart, S.R., Martin-Mazuelos, E., Meis, J.F., Melhem, M.S.C., Ostrosky-Zeichner, L., Pelaez, T., Szeszs, M.W., St-Germain, G., Bonfietti, L.X., Guarro, J., Turnidge, J. 2014. Multilaboratory study of epidemiological cutoff values for detection of resistance in eight Candida species to fluconazole, posaconazole, and voriconazole. Antimicrobial Agents and Chemotherapy 58(4): 2006-2012.

Freile, M.L., Giannini, F., Pucci, G., Sturniolo, A., Rodero, L., Pucci, O., Balzareti, V., Enriz, R.D.
2003. Antimicrobial activity of aqueous extracts and of berberine isolated from Berberis heterophylla. Fitoterapia 74(7-8): 702-705.

Fujii, A., Okuyama, T., Wakame, K., Okumura, T., Ikeya, Y., Nishizawa, M. 2017. Identification of anti-inflammatory constituents in Phellodendri Cortex and Coptidis Rhizoma by monitoring the suppression of nitric oxide production. Journal of Natural Medicines 71(4): 745-756.

Gonçalves, M.J., Piras, A., Porcedda, S., Marongiu, B., Falconieri, D., Cavaleiro, C., Rescigno, A., Rosa, A., Salgueiro, L. 2015. Antifungal activity of extracts from Cynomorium coccineum growing wild in Sardinia island (Italy). Natural Product Research 29(23): 2247-2250.

González, G.M., Robledo, E., Garza-González, E., Elizondo, M., González, J.G. 2009. Efficacy of albaconazole against Candida albicans in a vaginitis model. Antimicrobial Agents and Chemotherapy 53(10): 4540-4541.

Ham, Y., An, J.E., Lee, S.M., Chung, S.H., Kim, S.H., Park, M.J. 2021. Isolation and identification of fungi associated with decay of Quercus mongolica. Journal of the Korean Wood Science and Technology 49(3): 234-253.

Hammer, K.A., Carson, C.F., Riley, T.V. 2004. Antifungal effects of Melaleuca alternifolia (tea tree) oil and its components on Candida albicans, Candida glabrata and Saccharomyces cerevisiae. Journal of Antimicrobial Chemotherapy 53(6): 1081-1085.

Hassan, H.A., Genaidy, M.M., Kamel, M.S., Abdelwahab, S.F. 2020. Synergistic antifungal activity of mixtures of clove, cumin and caraway essential oils and their major active components. Journal of Herbal Medicine 24: 100399.

Hidayat, A., Turjaman, M., Faulina, S.A., Ridwan, F., Najmulah, A.A., Irawadi, T.T., Iswanto, A.H. 2019. Antioxidant and antifungal activity of endophytic fungi associated with agarwood trees. Journal of the 
Korean Wood Science and Technology 47(4): 459471.

Irfan, M., Alam, S., Manzoor, N., Abid, M. 2017. Effect of quinoline based 1,2,3-triazole and its structural analogues on growth and virulence attributes of Candida albicans. PLOS ONE 12(4): e0175710.

Jiang, Y., Vaysse, J., Gilard, V., Balayssac, S., Déjean, S., Malet-Martino, M., David, B., Fiorini, C., Barbin, Y. 2012. Quality assessment of commercial Magnoliae Officinalis Cortex by ${ }^{1} \mathrm{H}-\mathrm{NMR}$-based metabolomics and HPLC methods. Phytochemical Analysis 23(4): 387-395.

Jung, H.C. 2019. Enhancement of laccase production from wood-rotting fungus by co-culture with Trichoderma longibrachiatum. Journal of the Korean Wood Science and Technology 47(2): 210-220.

Khan, M.S.A., Ahmad, I., Cameotra, S.S. 2013. Phenyl aldehyde and propanoids exert multiple sites of action towards cell membrane and cell wall targeting ergosterol in Candida albicans. AMB Express 3(1): 54 .

Kim, J., Bao, T.H.Q., Shin, Y.K., Kim, K.Y. 2018. Antifungal activity of magnoflorine against Candida strains. World Journal of Microbiology and Biotechnology 34(11): 167.

Kim, J.H., Weeratunga, P., Kim, M.S., Nikapitiya, C., Lee, B.H., Uddin, M.B., Kim, T.H., Yoon, J.E., Park, C., Ma, J.Y., Kim, H., Lee, J.S. 2016. Inhibitory effects of an aqueous extract from Cortex Phellodendri on the growth and replication of broad-spectrum of viruses in vitro and in vivo. BMC Complementary and Alternative Medicine 16(1): 265.

Kim, K.S., Kim, H.C. 2004. Analytical method for the determination of standard compounds in oriental medicine materials listed in the Korean Pharmacopoeia (KPVIII). The Korean Society of Crop Science 49(spc1): 117-145.

Kumar, A., Ekavali, Chopra, K., Mukherjee, M.,
Pottabathini, R., Dhull, D.K. 2015. Current knowledge and pharmacological profile of berberine: An update. European Journal of Pharmacology 761: 288-297.

Kuo, C.L., Chi, C.W., Liu, T.Y. 2004. The anti-inflammatory potential of berberine in vitro and in vivo. Cancer Letters 203(2): 127-137.

Landers, D.V., Wiesenfeld, H.C., Heine, R.P., Krohn, M.A., Hillier, S.L. 2004. Predictive value of the clinical diagnosis of lower genital tract infection in women. American Journal of Obstetrics and Gynecology 190(4): 1004-1008.

Lee, H.S., Kim, Y. 2016. Antifungal activity of Salvia miltiorrhiza against Candida albicans is associated with the alteration of membrane permeability and (1,3)- $\beta$-D-glucan synthase activity. Journal of Microbiology and Biotechnology 26(3): 610-617.

Lee, S.Y., Lee, D.S., Cho, S.M., Kim, J.C., Park, M.J., Choi, I.G. 2021. Antioxidant properties of 7 domestic essential oils and identification of physiologically active components of essential oils against Candida albicans. Journal of the Korean Wood Science and Technology 49(1): 23-43.

Leite, M.C.A., Bezerra, A.P.B., de Sousa, J.P., Guerra, F.Q.S., Lima, E.O. 2014a. Evaluation of antifungal activity and mechanism of action of citral against Candida albicans. Evidence-Based Complementary and Alternative Medicine 2014: 378280.

Leite, M.C.A., de Brito Bezerra, A.P., de Sousa, J.P., de Oliveira Lima, E. 2014b. Investigating the antifungal activity and mechanism(s) of geraniol against Candida albicans strains. Medical Mycology 53(3): 275-284.

Lemar, K.M., Passa, O., Aon, M.A., Cortassa, S., Müller, C.T., Plummer, S., O'Rourke, B., Lloyd, D. 2005. Allyl alcohol and garlic (Allium sativum) extract produce oxidative stress in Candida albicans. Microbiology 151(10): 3257-3265.

Li, Y., Jiao, P., Li, Y., Gong, Y., Chen, X., Sun, S. 
2019. The synergistic antifungal effect and potential mechanism of D-penicillamine combined with fluconazole against Candida albicans. Frontiers in Microbiology 10: 2853.

Lum, K.Y., Tay, S.T., Le, C.F., Lee, V.S., Sabri, N.H., Velayuthan, R.D., Hassan, H., Sekaran, S.D. 2015. Activity of novel synthetic peptides against Candida albicans. Scientific Reports 5(1): 9657.

Luo, H., Wu, H., Yu, X., Zhang, X., Lu, Y., Fan, J., Tang, L., Wang, Z. 2019. A review of the phytochemistry and pharmacological activities of Magnoliae Officinalis Cortex. Journal of Ethnopharmacology 236: 412-442.

Masomi, F., Hassanshahian, M. 2016. Antimicrobial activity of five medicinal plants on Candida albicans. The Iranian Journal of Toxicology 10(6): 39-43.

Min, B.S., Bang, K.H., Lee, J.S., Bae, G.H. 1996. Screening of the antifungal activity from natural products against Candida albicans and Penicillium avellaneum. Yakhak Hoeji 40(5): 582-590.

Miron, D., Battisti, F., Silva, F.K., Lana, A.D., Pippi, B., Casanova, B., Gnoatto, S., Fuentefria, A., Mayorga, P., Schapoval, E.E.S. 2014. Antifungal activity and mechanism of action of monoterpenes against dermatophytes and yeasts. Revista Brasileira de Farmacognosia 24(6): 660-667.

Ng, K.P., Kuan, C.S., Kaur, H., Na, S.L., Atiya, N., Velayuthan, R.D. 2015. Candida species epidemiology 2000-2013: A laboratory-based report. Tropical Medicine \& International Health 20(11): 1447-1453.

Ni, H., Cai, X., Qiu, X., Liu, L., Ma, X., Wan, L., Ye, H., Chen, L. 2020. Biphenyl-type neolignans from stem bark of Magnolia officinalis with potential anti-tumor activity. Fitoterapia 147: 104769.

Oufensou, S., Scherm, B., Pani, G., Balmas, V., Fabbri, D., Dettori, M.A., Carta, P., Malbrán, I., Migheli, Q., Delogu, G. 2019. Honokiol, magnolol and its monoacetyl derivative show strong anti-fungal effect on Fusarium isolates of clinical relevance. PLOS ONE 14(9): e0221249.

Park, J., Lee, J., Jung, E., Park, Y., Kim, K., Park, B., Jung, K., Park, E., Kim, J., Park, D. 2004a. In vitro antibacterial and anti-inflammatory effects of honokiol and magnolol against Propionibacterium sp. European Journal of Pharmacology 496(1-3): 189195.

Park, K.S., Kang, H.I., Lee, J.W., Paik, Y.K. $2004 b$. Anti-Candida activity of YH-1715R, a new triazole derivative. Journal of Microbiology and Biotechnology 14(4): 693-697.

Park, K.S., Kang, K.C., Kim, J.H., Adams, D.J., Johng, T.N., Paik, Y.K. 1999. Differential inhibitory effects of protoberberines on sterol and chitin biosyntheses in Candida albicans. Journal of Antimicrobial Chemotherapy 43(5): 667-674.

Parray, H.A., Lone, J., Park, J.P., Choi, J.W., Yun, J.W. 2018. Magnolol promotes thermogenesis and attenuates oxidative stress in 3T3-L1 adipocytes. Nutrition 50: 82-90.

Patel, M., Coogan, M.M. 2008. Antifungal activity of the plant Dodonaea viscosa var. angustifolia on Candida albicans from HIV-infected patients. Journal of Ethnopharmacology 118(1): 173-176.

Pfaller, M., Chaturvedi, V., Espinel-Ingroff, A., Ghannoum, M.A., Gosey, L.L., Odds, F.C. 2008a. Reference method for broth dilution antifungal susceptibility testing of yeasts; approved standardsecond edition. CLSI document M27-A2. The Clinical and Laboratory Standards Institute: Malvern, PA, USA.

Pfaller, M.A., Diekema, D.J. 2007. Epidemiology of invasive candidiasis: A persistent public health problem. Clinical Microbiology Reviews 20(1): 133163.

Pfaller, M.A., Diekema, D.J., Ostrosky-Zeichner, L., Rex, J.H., Alexander, B.D., Andes, D., Brown, S.D., Chaturvedi, V., Ghannoum, M.A., Knapp, C.C., 
Sheehan, D.J., Walsh, T.J. 2008b. Correlation of MIC with outcome for Candida species tested against caspofungin, anidulafungin, and micafungin: Analysis and proposal for interpretive MIC breakpoints. Journal of Clinical Microbiology 46(8): 2620-2629.

Pristov, K.E., Ghannoum, M.A. 2019. Resistance of Candida to azoles and echinocandins worldwide. Clinical Microbiology and Infection 25(7): 792-798.

Rajkowska, K., Nowak, A., Kunicka-Styczyńska, A., Siadura, A. 2016. Biological effects of various chemically characterized essential oils: Investigation of the mode of action against Candida albicans and HeLa cells. RSC Advances 6(99): 97199-97207.

Ramamourthy, G., Park, J., Seo, C., Vogel, H.J., Park, Y. 2020. Antifungal and antibiofilm activities and the mechanism of action of repeating lysine-tryptophan peptides against Candida albicans. Microorganisms 8(5): 758.

Rex, J.H., Rinaldi, M.G., Pfaller, M.A. 1995. Resistance of Candida species to fluconazole. Antimicrobial Agents and Chemotherapy 39(1): 1-8.

Richter, S.S., Galask, R.P., Messer, S.A., Hollis, R.J., Diekema, D.J., Pfaller, M.A. 2005. Antifungal susceptibilities of Candida species causing vulvovaginitis and epidemiology of recurrent cases. Journal of Clinical Microbiology 43(5): 2155-2162.

Ryuk, J.A., Zheng, M.S., Lee, M.Y., Seo, C.S., Li, Y., Lee, S.H., Moon, D.C., Lee, H.W., Lee, J.H., Park, J.Y., Son, J.K., Ko, B.S. 2012. Discrimination of Phellodendron amurense and $P$. chinense based on DNA analysis and the simultaneous analysis of alkaloids. Archives of Pharmacal Research 35(6): 1045-1054.

Saag, M.S., Dismukes, W.E. 1988. Azole antifungal agents: Emphasis on new triazoles. Antimicrobial Agents and Chemotherapy 32(1): 1-8.

Saito, J., Fukushima, H., Nagase, H. 2009. Anti-clastogenic effect of magnolol-containing Hange-koboku-to,
Dai-joki-to, Goshaku-san, and Magnoliae Cortex on benzo(a)pyrene-induced clastogenicity in mice. Biological and Pharmaceutical Bulletin 32(7): 12091214.

Sandven, P. 2000. Epidemiology of candidemia. Revista Iberoamericana de Micologia 17(3): 73-81.

Sanglard, D., Coste, A.T. 2016. Activity of isavuconazole and other azoles against Candida clinical isolates and yeast model systems with known azole resistance mechanisms. Antimicrobial Agents and Chemotherapy 60(1): 229-238.

Serra, E., Hidalgo-Bastida, L.A., Verran, J., Williams, D., Malic, S. 2018. Antifungal activity of commercial essential oils and biocides against Candida albicans. Pathogens 7(1): 15.

Shai, L.J., McGaw, L.J., Masoko, P., Eloff, J.N. 2008. Antifungal and antibacterial activity of seven traditionally used South African plant species active against Candida albicans. South African Journal of Botany 74(4): 677-684.

Sharon, V., Fazel, N. 2010. Oral candidiasis and angular cheilitis. Dermatologic Therapy 23(3): 230-242.

Shen, P., Zhang, Z., He, Y., Gu, C., Zhu, K., Li, S., Li, Y., Lu, X., Liu, J., Zhang, N., Cao, Y. 2018. Magnolol treatment attenuates dextran sulphate sodium-induced murine experimental colitis by regulating inflammation and mucosal damage. Life Sciences 196: 69-76.

Soliman, S.S.M., Semreen, M.H., El-Keblawy, A.A., Abdullah, A., Uppuluri, P., Ibrahim, A.S. 2017. Assessment of herbal drugs for promising antiCandida activity. BMC Complementary Medicine and Therapies 17(1): 257.

Soll, D.R., Galask, R., Schmid, J., Hanna, C., Mac, K., Morrow, B. 1991. Genetic dissimilarity of commensal strains of Candida spp. carried in different anatomical locations of the same healthy women. Journal of Clinical Microbiology 29(8): 1702-1710. Sun, L., Liao, K., Wang, D. 2015a. Effects of magnolol 
and honokiol on adhesion, yeast-hyphal transition, and formation of biofilm by Candida albicans. PLOS ONE 10(2): e0117695.

Sun, L., Sun, S., Cheng, A., Wu, X., Zhang, Y., Lou, H. 2009. In vitro activities of retigeric acid B alone and in combination with azole antifungal agents against Candida albicans. Antimicrobial Agents and Chemotherapy 53(4): 1586-1591.

Sun, L.M., Liao, K., Liang, S., Yu, P.H., Wang, D.Y. 2015b. Synergistic activity of magnolol with azoles and its possible antifungal mechanism against Candida albicans. Journal of Applied Microbiology 118(4): 826-838.

Sun, Y., Lenon, G.B., Yang, A.W.H. 2019. Phellodendri Cortex: A phytochemical, pharmacological, and pharmacokinetic review. Evidence-Based Complementary and Alternative Medicine 2019: 7621929.

Suprapti, S., Djarwanto, D., Listya Mustika, D. 2020. Determining the wood (Parashorea spp.) decaying and metal corroding abilities of eight fungi. Journal of the Korean Wood Science and Technology 48(1): $50-60$.

Tampieri, M.P., Galuppi, R., Macchioni, F., Carelle, M.S., Falcioni, L., Cioni, P.L., Morelli, I. 2005. The inhibition of Candida albicans by selected essential oils and their major components. Mycopathologia 159(3): 339-345.

Taylor, M., Raja, A. 2021. Oral Candidiasis. In: StatPearls. StatPearls Publishing: Treasure Island, FL, USA.

Tian, X., Xu, Z., Hu, P., Yu, Y., Li, Z., Ma, Y., Chen, M., Sun, Z., Liu, F., Li, J., Huang, C. 2020. Determination of the antidiabetic chemical basis of Phellodendri Chinensis Cortex by integrating hepatic disposition in vivo and hepatic gluconeogenese inhibition in vitro. Journal of Ethnopharmacology 263: 113215.

Tsai, T.H., Chen, C.F. 1992. Identification and determination of honokiol and magnolol from Magnolia officinalis by high-performance liquid chromatography with phtodiode-array UV detection. Journal of Chromatography A 598(1): 143-146.

Vincent-Ballereau, F.N., Patey, O.N., Lafaix, C. 1991. Fluconazole: Review and situation among antifungal drugs in the treatment of opportunistic mycoses of human immuno-deficiency virus infections. Pharmaceutisch Weekblad 13(2): 45-57.

Violante, I.M.P., Hamerski, L., Garcez, W.S., Batista, A.L., Chang, M.R., Pott, V.J., Garcez, F.R. 2012. Antimicrobial activity of some medicinal plants from the cerrado of the central-western region of Brazil. Brazilian Journal of Microbiology 43(4): 1302-1308.

Wang, K., Dang, W., Xie, J., Zhu, R., Sun, M., Jia, F., Zhao, Y., An, X., Qiu, S., Li, X., Ma, Z., Yan, W., Wang, R. 2015. Antimicrobial peptide protonectin disturbs the membrane integrity and induces ROS production in yeast cells. Biochimica et Biophysica Acta (BBA) - Biomembranes 1848(10 Pt A): 23652373.

Whaley, S.G., Berkow, E.L., Rybak, J.M., Nishimoto, A.T., Barker, K.S., Rogers, P.D. 2017. Azole antifungal resistance in Candida albicans and emerging non-albicans Candida species. Frontiers in Microbiology 7: 2173.

Xian, Y.F., Lin, Z.X., Ip, S.P., Su, Z.R., Chen, J.N., Lai, X.P. 2013. Comparison the neuropreotective effect of Cortex Phellodendri chinensis and Cortex Phellodendri amurensis against beta-amyloid-induced neurotoxicity in PC12 cells. Phytomedicine 20(2): 187-193.

Xie, Y., Liu, X., Zhou, P. 2020. In vitro antifungal effects of berberine against Candida spp. in planktonic and biofilm conditions. Drug Design, Development and Therapy 14: 87-101.

Xu, B., Yan, Y., Huang, J., Yin, B., Pan, Y., Ma, L. 2020. Cortex Phellodendri extract's anti-diarrhea effect in mice related to its modification of gut 
microbiota. Biomedicine and Pharmacotherapy 123: 109720.

Yamamoto, T., Umegawa, Y., Tsuchikawa, H., Hanashima, S., Matsumori, N., Funahashi, K., Seo, S., Shinoda, W., Murata, M. 2019. The amphotericin B-ergosterol complex spans a lipid bilayer as a single-length assembly. Biochemistry 58(51): 5188-5196.

Yapar, N. 2014. Epidemiology and risk factors for invasive candidiasis. Therapeutics and Clinical Risk Management 10: 95-105.

Yoon, J., Kim, T.J. 2021. Synergistic antifungal activity of Magnoliae Cortex and Syzyii Flos against Candida albicans. Journal of the Korean Wood Science and Technology 49(2): 142-153.

Yun, J., Shin, H.C., Hwang, W.J., Yoon, S.M., Kim, Y.S. 2021. Identification of sapstain fungi on weathered wooden surfaces of buildings at Jangheung and Jeju island. Journal of the Korean Wood Science and Technology 49(6): 591-601.

Zazharskyi, V.V., Davydenko, P.O., Kulishenko, O.M., Borovik, I.V., Zazharska, N.M., Brygadyrenko, V.V. 2020. Antibacterial and fungicidal activities of ethanol extracts of 38 species of plants. Biosystems Diversity 28(3): 281-289.
Zhao, Y., Yan, D., Wang, J., Zhang, P., Xiao, X. 2010. Anti-fungal effect of berberine on Candida albicans by microcalorimetry with correspondence analysis. Journal of Thermal Analysis and Calorimetry 102(1): 49-55.

Zhou, P., Fu, J., Hua, H., Liu, X. 2017. In vitro inhibitory activities of magnolol against Candida spp. Drug Design, Development and Therapy 11: 2653-2661.

Zhu, S., Dou, S., Liu, X., Liu, R., Zhang, W, Huang, H., Zhang, Y., Hu, Y., Wang, S. 2011. Qualitative and quantitative analysis of alkaloids in Cortex Phellodendri by HPLC-ESI-MS/MS and HPLC-DAD. Chemical Research in Chinese Universities 27(1): 38-44.

Zida, A., Bamba, S., Yacouba, A., Ouedraogo-Traoré, R., Guiguemde, R.T. 2017. Anti-Candida albicans natural products, sources of new antifungal drugs: A review. Journal de Mycologie Médicale 27(1): 1-19.

Zorić, N., Kosalec, I., Tomić, S., Bobnjarić, I., Jug, M., Vlainić, T., Vlainić, J. 2017. Membrane of Candida albicans as a target of berberine. BMC Complementary Medicine and Alternative Medicin 17(1): 268. 